\title{
Communicating Science Concepts to Individuals with Visual Impairments using Short Learning Modules
}

Anthony S. Stender, ${ }^{1}$ Ryan Newell, ${ }^{1}$ Eduardo Villarreal, ${ }^{1}$ Dayne F. Swearer,${ }^{2}$ Elisabeth Bianco, ${ }^{2}$ and Emilie Ringe ${ }^{1,2 *}$

${ }^{1}$ Department of Materials Science and NanoEngineering, Rice University, 6100 Main Street, Houston, TX 77005, United States

${ }^{2}$ Department of Chemistry, Rice University, 6100 Main Street, Houston, TX 77005, United States

\section{ABSTRACT}

Of the 6.7 million individuals in the United States who are visually impaired, $63 \%$ are unemployed, and 59\% have not attained an education beyond a high school diploma. Providing a basic science education to children and adults with visual disabilities can be challenging, because most scientific learning relies on visual demonstrations. Creating resources to help teachers and service organizations better communicate science is thus critical both to the education of sighted students as well as to the continuing education of individuals with blindness or low vision (BLV). Here, 4 new scientific learning activities that last 5 to 15 minutes each are described. These simple exercises are designed to educate the general public, including both those who are sighted and those with BLV. The modules use tactile and auditory approaches to convey basic concepts including: the metric system, material strength and deformation, transparency, and the electromagnetic spectrum. These modules were tested on 20 adults with BLV during a science outreach event. Answers to learning assessment questions indicate that the modules conveyed information about the scientific concepts presented and increased an interest in science for most participants. 
GRAPHICAL ABSTRACT

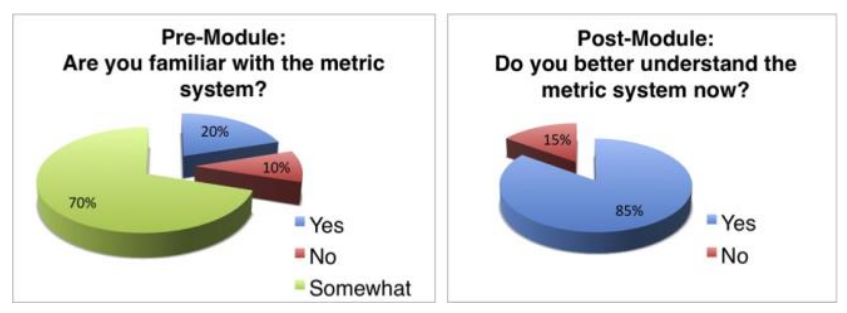

\section{KEYWORDS}

General Public, High School/Introductory Chemistry, Public Understanding/Outreach, Laboratory Instruction, Hands-on Learning/Manipulatives, Materials Science, Laboratory Equipment/Apparatus, Solids.

\section{BACKGROUND}

In the U.S., 6.7 million individuals are visually impaired, of which $63 \%$ are unemployed and 59\% have not progressed beyond a high school degree. ${ }^{1-3}$ Providing science education to children and adults with visual disabilities not only entails finding ways to reach and engage them, it often requires a complete redesign of traditional activities. Recent advances in academic contexts have provided new opportunities to facilitate science education of students with visual disabilities ${ }^{4-8}$ and to encourage those who wish to pursue STEM careers. ${ }^{8}$ Guidelines on appropriate assistant strategies, as well as novel technologies, help instructors adapt various activities and scientific topics. ${ }^{9-17}$ These resources are an essential aspect of creating a diverse and educated workforce; however, such resources are still limited in number, size, and scope.

Previously published activities for individuals with blindness or low vision (BLV) 6-9 focus on formal education of young students, either in the classroom or during summer camps held in schools. The motivation of this work is to provide a different set of activities that can be used in informal settings and deliver science education and exposure to audiences with a variety of backgrounds (including age, sightedness, education, etc.). The activities had to be safe, simple, easy to transport and set up, and produce little to no waste. Herein we report on 4 short modules primarily intended for the continuing education of the general public in informal settings. 
These modules use tactile and auditory approaches to convey the following basic concepts: the metric system, material strength and deformation, transparency of materials, and the electromagnetic spectrum.

Below we describe how these 4 modules were utilized during a 3-hour science outreach event reaching 20 BLV adults with diverse educational backgrounds. Prior to that event, a series of preliminary events were conducted at Rice University with blindfolded undergraduates and two BLV individuals, including a Ph.D. scientist. The feedback obtained was used to refine the modules and their discussion points before to presenting the modules at the Lighthouse of Houston.

The participants were asked simple questions before, during, and after the modules to assess the effectiveness of the activity in promoting interest in, and knowledge of, science. The results indicate that the modules were successful in teaching a variety of basic scientific concepts, and the participants were eager to have us return with additional activities in the future.

\section{PARTICIPANTS}

The Lighthouse of Houston is a nonprofit community center located in Houston, TX, that serves BLV individuals. A science day was planned and advertised to the clients and staff of the Houston Lighthouse, welcoming them to come try the newly developed science modules. Following Rice University's Institutional Review Board (IRB) approved protocol, 20 participants were read a consent form prior to starting the modules and signed the form on their own. Participants were all BLV adults; their level of education and mental aptitude varied widely. The questions were asked verbally before, during, and after the modules, and participant's responses were recorded anonymously by the demonstrators (during) or the activity coordinator (before/after). Note that some (3) participants left without completing all the modules due to time constraints, such 20 participants completed the Metric System module, 20 completed the Materials Transparency module, 19 completed the Materials Strength module, and 17 completed the Hearing the Electromagnetic Spectrum module. 


\section{DESCRIPTION OF MODULES AND RESULTS}

The first module performed with all participants was the Metric System module, because the concepts of length and scale that are communicated in it serve as an introduction to the other 3 modules. Due to the varying lengths of time required by the different modules, participants were directed through the next two modules in no particular order: Materials Transparency and Strength of Materials. The Hearing the Electromagnetic Spectrum module was always performed last due to its higher level of difficulty. Each module was performed with one demonstrator and one participant to maximize learning and for greater ease of acquiring feedback. Short descriptions of the modules and discussion of the results are presented here. Complete guides to building and performing each module are available in the Supporting Information.

\section{Pre-Activity Questions}

Before going to the first module, 19 of the 20 participants were asked two simple "yes or no" style questions by the activity coordinator, although one participant expressed only being "somewhat" interested in science. One of the day's participants started the first module before the questions were asked, so that person was not included in this survey. The answers (Table 1) indicate that most participants had previously heard the term "nano" (relevant to the Metric System module) and were interested in science.

Table 1. Answers to the Pre-Activity Questions from 19 Participants

$\begin{array}{llll}\text { Question } & \text { Yes } & \text { Somewhat } & \text { No } \\ \text { Are you interested in science? } & 16 & 1 & 2 \\ \text { Are you familiar with the term } & 13 & 0 & 6 \\ \text { "nano"? } & & & 6\end{array}$
"nano"?

Metric System Module

The United States primarily relies on the units of measurement known as the U.S. Customary system, making it one of the 3 countries in the world (with Myanmar and Liberia) that has not adopted the metric system. ${ }^{18}$ Therefore, a significant fraction of the U.S. population is not well-informed about the metric system even though it is 
commonly used when teaching chemistry and other scientific topics in a classroom. Moreover, nanotechnology is constantly growing in its importance to scientific research and society, many of the participants had heard of concepts related to nanotechnology (13/19, Table 1). While the novel physical properties enabled by nanoscale materials and chemical processes are independent of the system of measurement used, the very name "nano" used to describe the length scale where these properties emerge is rooted in the International System of Units' length nomenclature $\left(1 \mathrm{~nm}=10^{-9} \mathrm{~m}\right)$. Therefore, understanding what is nano goes hand-in-hand with understanding the metric system; this module addresses both concepts.

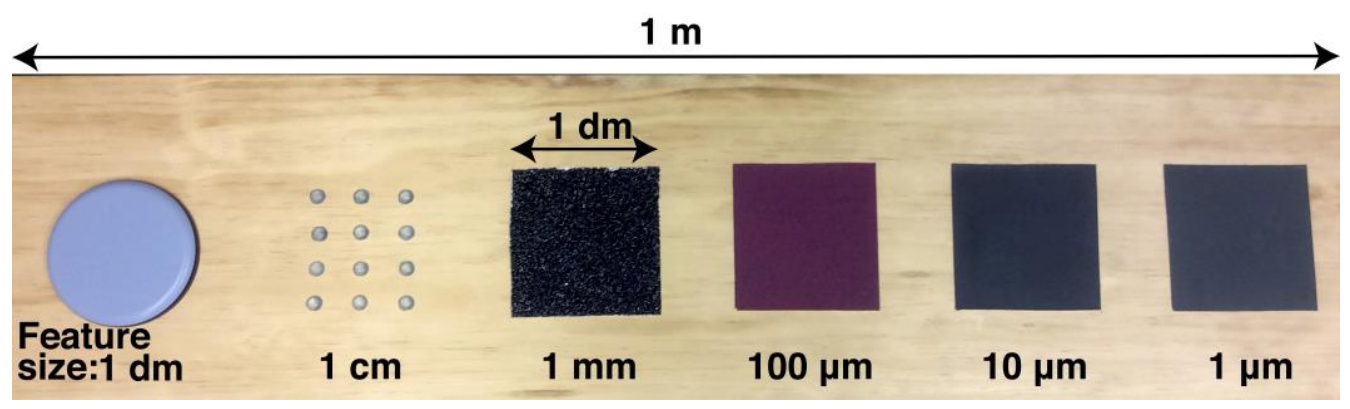

Figure 1. Design of the Metric System module.

Touch is utilized in this module to explore length scales, making it appropriate for BLV and non-BLV individuals alike. A $1 \mathrm{~m}$ long wooden board is decorated with several objects, each with smaller features than the previous by a factor of 10 (Fig. 1). For this purpose, we used one $1 \mathrm{dm}$ rubber disk, an array of $1 \mathrm{~cm}$ diameter rubber disks, and cutouts of P20 (ISO scale), 150 (CAMI scale), 1000 (CAMI scale), and 2000 (CAMI scale) grit sandpaper corresponding to 1000, 100, 10, and $1 \mu \mathrm{m}$ sand particle sizes. During the demonstration, the participants explore the objects on the board, while the demonstrator brings their attention to the factors of 10 between the features' sizes (Fig. 2). To include a discussion of the nanoscale, participants are told that the lower end of the nanoscale includes objects that are another three orders of magnitude below the smallest features on the board. At that point, the demonstrator and 
participant have several minutes remaining in which to further discuss the concepts covered during the demonstration.

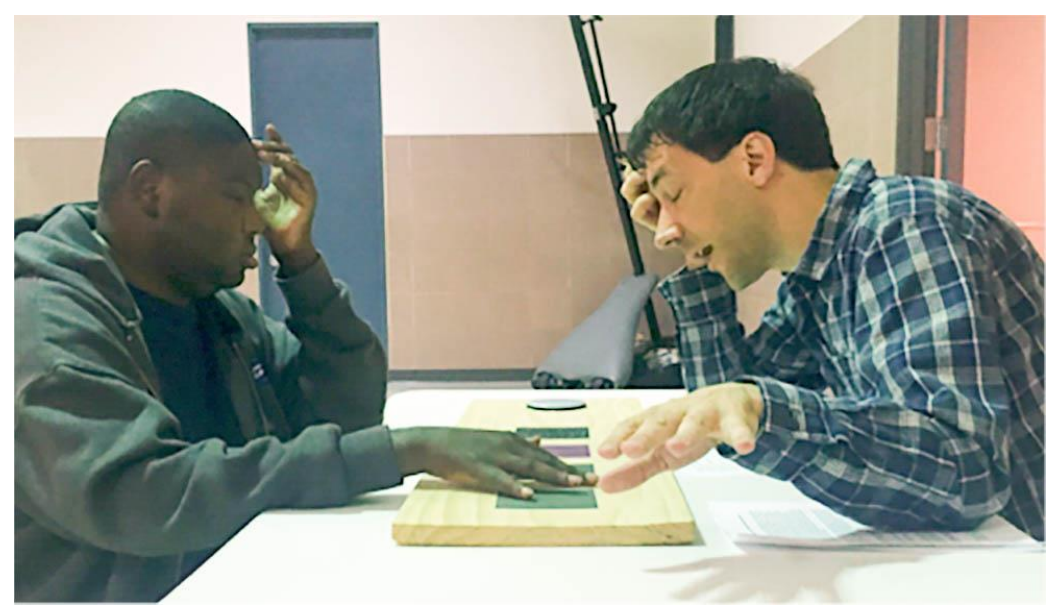

Figure 2. A participant (left) and demonstrator (right) performing the Metric System module.

The module typically lasted about 5 to 10 minutes and generated much interest due to its stimulating tactile features. It was found that, despite preliminary concerns, most (16 out of 20) participants could distinguish between the 10 and $1 \mu \mathrm{m}$ sandpaper.

Before the module started, all 20 participants were asked about their familiarity with the metric system. Most participants had "heard of it" but only 4 had a "good understanding of it" (Table 2). After the module, the participants were asked whether they had a better understanding of the metric system; the majority answered "yes" (Table 2). The 3 participants answering "about the same" had a prior good understanding of the metric system. Given this feedback, we conclude that this module is effective at introducing the metric system and the size of the nanoscale to a general audience in an informal setting.

Table 2. Answers to the Metric System Questions from 20

Participants

\begin{tabular}{|l|lll} 
Pre-module question & Yes & Heard of it & No \\
\hline Are you familiar with the metric system? & 4 & 14 & 2 \\
\hline Post-module question & Yes & Same & No \\
\hline Do you have a better understanding of the & 17 & 3 & 0
\end{tabular}
metric system now? 


\section{Materials Transparency Module}

Transparent materials are critical to the transmission of light, and they are critical in a broad range of settings from everyday life (e.g., windows, cell phone screens) to advanced technology (e.g., solar cells). In the context of chemistry, transmission of light is relevant to extinction spectroscopy and the concentration of a solution. Moreover, loss of transparency within the eye lens due to cataracts is the leading cause of blindness in the world, ${ }^{19}$ making transparency relevant to vision. In this module, the concepts of transparency, translucency, and opaqueness are described without visual aids to provide an understanding of the concepts surrounding light transmission to BLV individuals.

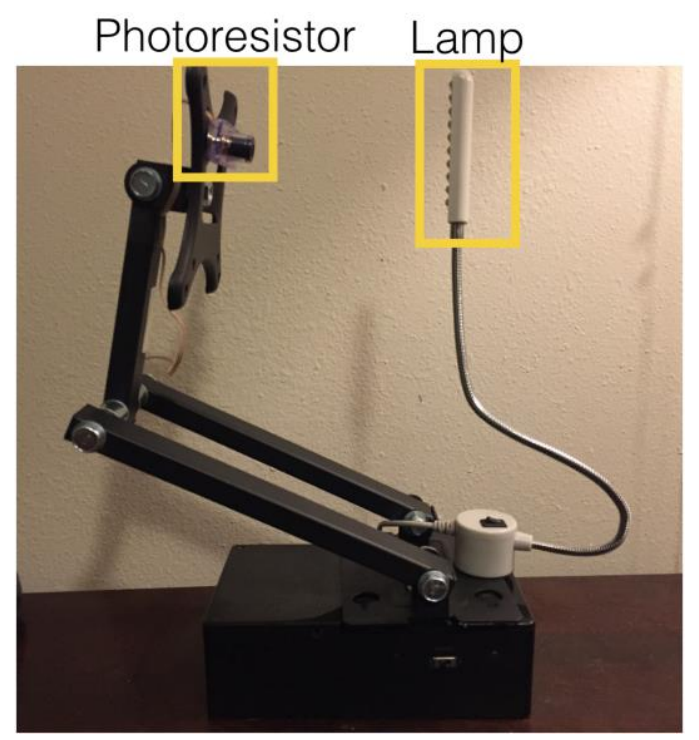

Figure 3. The photoresistor and lamp setup for the materials transparency module.

This module consists of a reading lamp facing a commercially available photodetector, spaced approximately $20-30 \mathrm{~cm}$ apart, as shown in Fig. 3. The photodetector is linked to an audio output (speakers or one-sided headphones) via a sound-generation integrated circuit; the output volume decreases as less light is sensed at the photodetector. The participants are given everyday objects, including paper, 
cardboard, cell phone screens, and rounded pieces of glass. After the demonstrator describes the setup to the participants, they are encouraged to insert the objects into the light path (placing the objects in front of the photodetector is the easiest approach as it avoids uncertainty about the light path and also blocks ambient light). The demonstrator then discusses the concept of light transmission with the participants.

Most (19 out of 20) of the participants responded "yes" when asked if they were familiar with the concept of transparency. The answers provided by the 20 participants to the post-module questions indicate that the module is successful at introducing and exemplifying transparency as well as translucency and opaqueness. Most participants reported a high post-module understanding of the concepts covered and high scores for their familiarity with transparent, translucent, and opaque materials (Table 3). All participants agreed that "the concepts were explained in a meaningful and informative way", that the "materials used in this module were representative of the three different kinds of materials covered", and that "the use of sound was helpful to represent light".

Table 3. Answers to the Post-Modules Question for the Materials Transparency Module from 20 Participants

$\begin{array}{llllll}\text { Question } & \begin{array}{l}\text { 1-Hard/ } \\ \text { Not } \\ \text { familiar }\end{array} & 2 & 3 & 4 & \begin{array}{l}\text { 5-Easy/ } \\ \text { Familiar }\end{array} \\ \begin{array}{l}\text { How easy was it for you to understand the } \\ \text { concepts covered in the module? }\end{array} & 0 & 0 & 1 & 5 & 14 \\ \begin{array}{l}\text { How familiar are you now with transparent, } \\ \text { translucent, and opaque materials? }\end{array} & 0 & 0 & 2 & 3 & 15\end{array}$

\section{Strength of Materials Module}

Early on in their education, college undergraduates in the sciences and

engineering learn about the properties and behaviors of materials, including strength, plastic/elastic deformation, and fatigue. These concepts are indeed central to our understanding of the world around us and dictate the choice of materials used for various applications. They are therefore relevant to the needs of the general public and everyday life. Polymers are ideal templates for explaining these concepts to a general audience. 


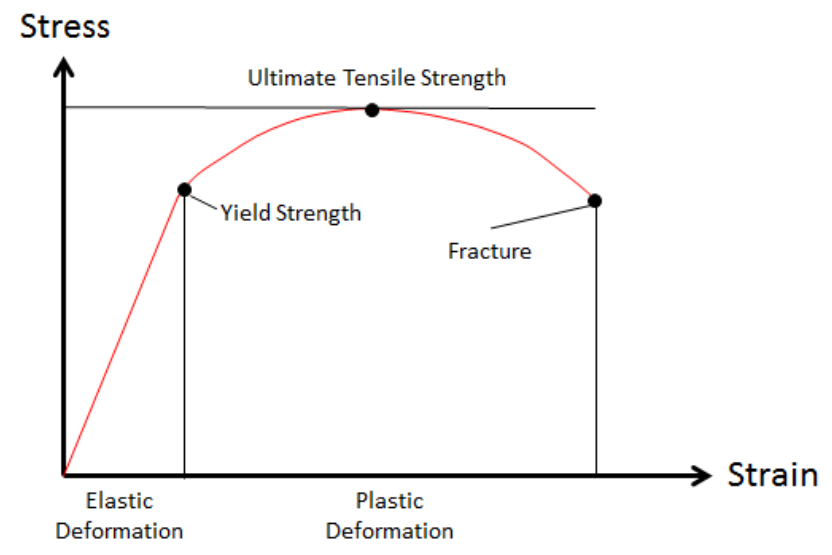

Figure 4. Stress/strain curve, showing that as more force (stress) is applied, more deformation (strain) results. Materials deform elastically, then plastically, and finally break. ${ }^{20}$

In this module, the participants explore materials that they encounter on a daily basis and learn how to describe their mechanical properties. ${ }^{20}$ The concepts of plastic and elastic deformation (Fig. 4) are introduced by asking participants to pull apart and contrast 4 different materials (modeling clay, 2 polymeric films with different polymer chain orientation, and the zipper of a re-sealable ziptop plastic bag, Fig. 5). Then, crackinduced failure is explored using paper (with and without a small initial crack), and fatigue is exemplified with a metal paper clip. This module required the most time, taking up to 15 minutes, as it involves multiple parts, and the participants were keen on discussing the relationship between the concepts learned and other materials in their lives (see full list of comments/questions in the Supplementary Information). 


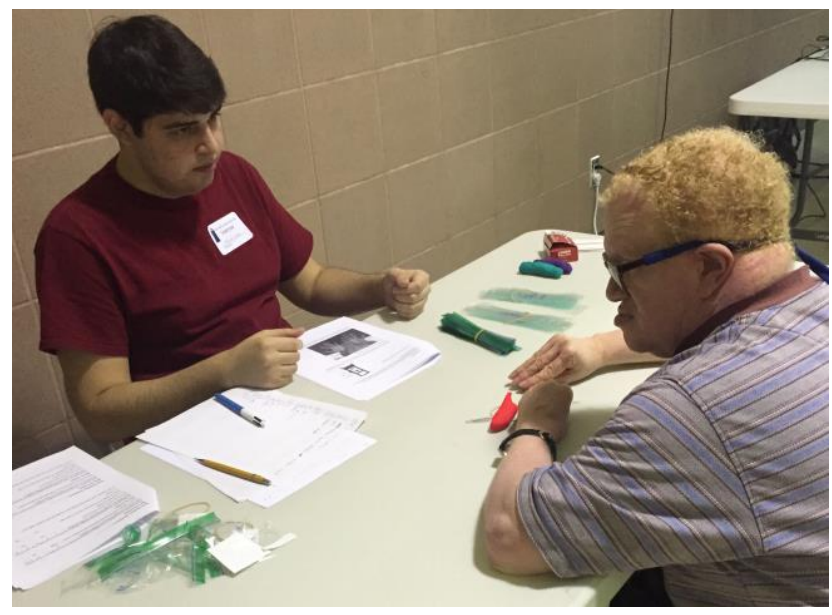

Figure 5. A demonstrator (left) and participant (right) performing the Strength of Materials module. The participant just completed a strength test on red modeling clay.

\section{Table 4. Answers to the Pre-Modules Question for the Strength of} Materials Module from 18 Participants

$\begin{array}{lllllll}\text { Question } & \begin{array}{l}\text { 1-No } \\ \text { knowledge }\end{array} & 2 & 3 & 4 & \begin{array}{l}5- \\ \text { Comprenhensive } \\ \text { knowledge }\end{array} \\ \begin{array}{l}\text { How much do you know about } \\ \text { the strength of materials? }\end{array} & 7 & 2 & 5 & 2 & 2 \\ \begin{array}{l}\text { Question } \\ \begin{array}{l}\text { Have you had any experience } \\ \text { with materials science before }\end{array}\end{array} & 7 & \text { Yes } & \text { No } & & & \\ \text { today? } & & 11 & & & \\ \end{array}$

Eighteen of the day's 20 participants went to this station. Before the module, the participants were asked about their prior knowledge of strength-based concepts and materials science, yielding wide-ranging answers (Table 4). The understanding of materials science gained through this module was then tested, and the results show that most participants can now recognize the concepts of plastic deformation, elastic deformation, and strength. Specifically, the majority of participants responded correctly to the 3 follow-up questions, as shown in Table 5. Note that 2 participants gave 2 answers, one correct and one incorrect, to the deformation question, and 3 participants gave one correct and up to 2 incorrect answers to the elastic question; these were all different participants and their answers were reported as "multiple" in Table 5. The 
concepts of cracking and fatigue were not assessed, but ensuing discussions indicated that several participants linked these to mechanical failure in cars and airplanes.

Table 5. Answers to the Post-Modules Questions for the Materials Strength Module from 18 Participants

\begin{tabular}{|c|c|c|c|c|c|}
\hline Question & $\begin{array}{l}\text { Modeling } \\
\text { clay }\end{array}$ & $\begin{array}{l}\text { Ziptop bag } \\
\text { (horizontal) }\end{array}$ & $\begin{array}{l}\text { Ziptop } \\
\text { bag } \\
\text { (vertical) }\end{array}$ & $\begin{array}{l}\text { Ziptop } \\
\text { bag } \\
\text { (zipper) }\end{array}$ & $\begin{array}{l}\text { None/No } \\
\text { answer/ } \\
\text { Multiple } \\
\text { answers }\end{array}$ \\
\hline $\begin{array}{l}\text { Which material, if any, } \\
\text { deformed the most } \\
\text { before failure? }\end{array}$ & $\begin{array}{l}10 \\
\text { (correct) }\end{array}$ & 1 & 2 & 2 & $0 / 1 / 2$ \\
\hline $\begin{array}{l}\text { Which material, if any, } \\
\text { felt the most elastic? }\end{array}$ & 0 & 2 & 3 & $\begin{array}{l}8 \\
\text { (correct) }\end{array}$ & $1 / 2 / 3$ \\
\hline $\begin{array}{l}\text { Which material, if any, } \\
\text { was the strongest? }\end{array}$ & 0 & 1 & 4 & $\begin{array}{l}12 \\
\text { (correct) }\end{array}$ & $0 / 1 / 0$ \\
\hline
\end{tabular}

Hearing the Electromagnetic Spectrum Module

Daily life is saturated with noise from the electromagnetic (EM) spectrum: from visible colors that decorate objects to the invisible signals of Wi-Fi, microwave ovens, and cell phones. Furthermore, the concepts of color, noise, and the EM spectrum are important to chemistry, particularly in spectroscopy and imaging. The wavelengths covered by the EM spectrum span an incredible range over $\sim 21$ orders of magnitude. For blind individuals, a small ( 1 order of magnitude) portion of the electromagnetic spectrum, the visible range, is hidden from perception. However, everyone is blind to the remainder of the electromagnetic spectrum.

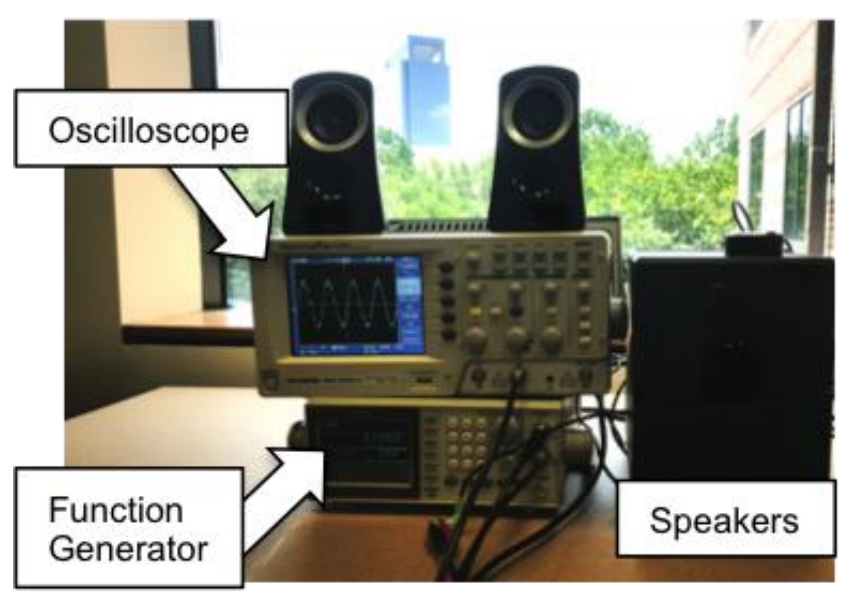

Figure 6. Instrument setup for the Hearing the Electromagnetic Spectrum module. 
In this module, EM waves are represented by sounds of different frequencies in order to explain the similarities between the various waves, visible and invisible. Even though EM and acoustic signals are different types of waves recorded by different organs (eyes vs. ears), they are both waves for which a limited range of energy can be detected by most humans. To demonstrate the EM spectrum, a function generator is connected to an oscilloscope and speakers (or headphones), providing visual and auditory signals, respectively (Figure 6). The acoustic frequency delivered by the function generator can be adjusted across a broad range; here the 1.5 to $10 \mathrm{kHz}$ range is chosen to comfortably match the human hearing range. The EM spectrum is then mapped onto this hearing range such that the longest EM wavelength discussed $\left(10^{8} \mathrm{~m}\right)$ is associated with the lowest acoustic frequency $(1,500 \mathrm{kHz})$, and the shortest $\left(10^{-12} \mathrm{~m}\right)$ with the highest acoustic frequency $(10,000 \mathrm{kHz})$. The participants heard the sounds in succession, and the demonstrator explained the corresponding EM waves (Figure 7 and Supplementary Information).

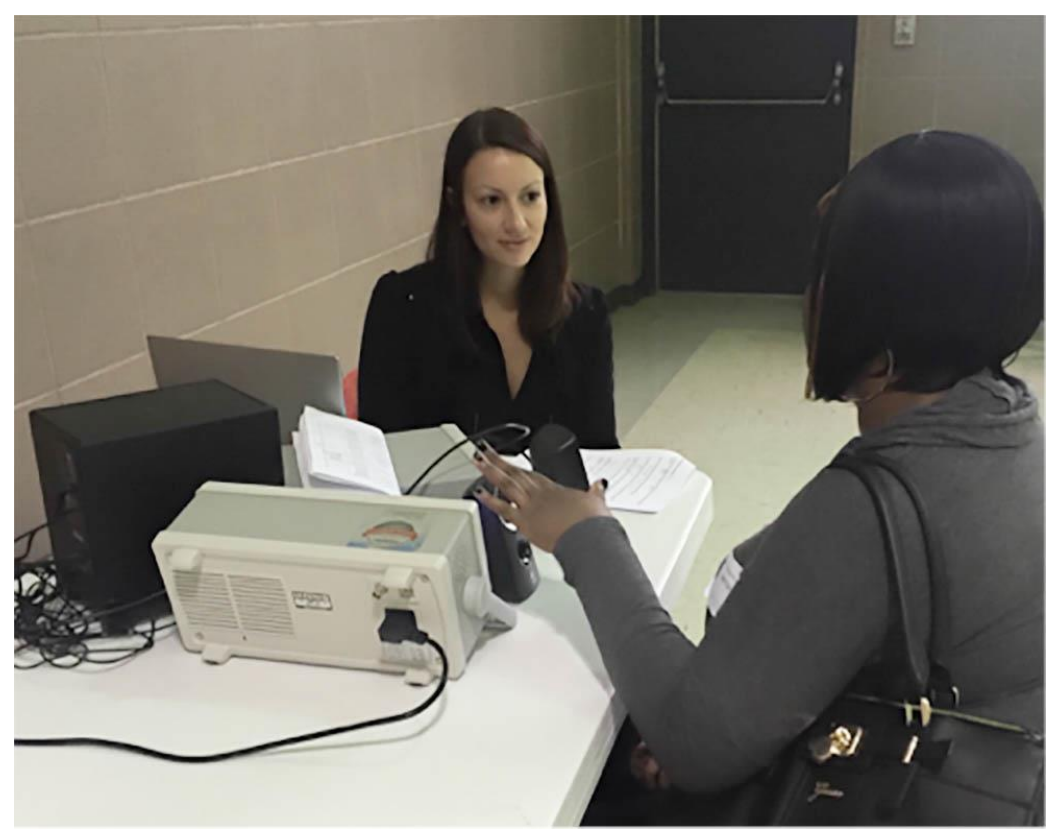

Figure 7. A demonstrator (left) and participant (right) performing the Hearing the Electromagnetic Spectrum module. 
Seventeen of the day's 20 participants went to this station. Before starting the module, the 17 participants were asked if they were familiar with the words "spectrum" and "radiation". Only one participant could describe the former. Most participants knew the word radiation from very specific contexts such as X-rays or UV radiation, and several articulated that radiation was detrimental to humans. Given such low level of knowledge, pre-module questions were limited to those two in favor of post-module assessment.

Participants were asked 5 post-module questions to test their newly acquired understanding (Table 6). The answers to the first 2 questions suggest that participants understand that the EM spectrum is more than light. Most of the participants also expressed that it was simple to understand that a higher sound pitch meant a higher radiation energy.

\section{Table 6. Answers to the Post-Modules Question for the Hearing the} Electromagnetic Spectrum Module from 17 Participants

$\begin{array}{llllll}\text { Question } & \text { 1-Not at all } & 2 & 3 & 4 & \text { 5-Very } \\ \text { How comfortable do you feel } & 0 & 0 & 2 & 0 & 15\end{array}$

about the concept that radiation is more than visible light?

$\begin{array}{llll}\text { Question } & \text { All } & \text { Some } & \text { None } \\ \text { According to what you learned } & 0 & \mathbf{1 3} & 4^{*} \\ \text { in this module, can people see } & & \text { (correct) } & \end{array}$

all, some, or none of the EM spectrum?

Question

Did you find it simple to

$\begin{array}{ll}\text { Yes } & \text { No } \\ 16 & 1^{\#}\end{array}$

understand that a higher sound

pitch means higher energy in

this module?

Do you feel you learned

something about the world

around you?"

*It is possible that the participant(s) referred to blind individuals

\#The participant who answered "no" to the higher sound/higher pitch question answered " 5 " to the concept of radiation question, however we suspect the participant did not understand the scale and meant " 1 " (results are reported as " 5 "). This participant had lower mental abilities than most, was the only one who could not name a form of radiation after the module, and reported not learning anything. 
To test the retention of the types of radiation discussed, the participants were also asked to name forms of radiation other than visible light: 13 provided only valid answers, 2 provided both valid and invalid answers, and 2 did not provide any valid answers (specific answers listed in the Supplementary Information). Finally, an openended question "Do you feel you learned something about the world around you?" was asked, to which 15 responded "yes" and described what they learned (answers reported in the Supplementary Information). Given the excellent responses to the post-module questions, we believe this module is a good introduction to the EM spectrum.

\section{Post-Activity Questions}

Upon completion of the 4 modules, the participants met again with the activity coordinator for a final discussion, which included 6 questions. The answers to "What parts of these lessons did you most enjoy" are reported in the Supplementary Information. Several participants mentioned that their favorite part of the activity was the Hearing the Electromagnetic Spectrum module (6 out of the 15 answers); however, this module was performed last, potentially introducing a significant bias. Otherwise, no clear trend appeared. The few answers to "What can be improved upon?" mostly related to the volume and high pitch sounds of the EM module and will be useful to the future implementation of and modifications to the program. The participants were also asked if they had suggestions for future modules; answers varied from biology to the planets. All participants were enthused to know that they will have more opportunities to experiment with science modules in the future.

Finally, to assess the success of the activity, the participants were asked if they learned anything during their visit and if the activity affected their interest in science. The results were very positive (Table 7), encouraging further module development to serve BLV individuals with broad educational backgrounds. 
Table 7. Answers to the Post-Activity Questions from 19

Participants

Question Yes Same No

Did you learn anything by $\quad 17 \quad 0 \quad 0$

participating?

Do you have a greater interest in $\quad \begin{array}{llll}11 & 6 & 0\end{array}$

science now?

\section{DISCUSSION AND CONCLUSIONS}

In addition to providing a fun activity to a group of individuals with visual disabilities, these modules provided a platform to learn basic concepts relevant to chemistry and the natural sciences. The answers and organization of the day also inspired a few improvements that will be implemented in future sessions.

To make the Metric System module stand-alone and enable distribution to service organizations, a Braille labeler was purchased and will be used to label each component and provide simple explanations. Any group interested in obtaining a board is encouraged to contact the corresponding author.

The sounds of the Materials Transparency and Hearing the Electromagnetic Spectrum modules, while not always on, can lead to a distracting environment. Onesided headphones can be used instead of speakers: several headsets can be connected to each unit by using an audio splitter, such that both the demonstrator and participant(s) hear the sound output without disturbing co-located modules.

The Strength of Materials module took roughly twice as long as the other modules, and consequently became a bottleneck for the flow of participants through the stations. Participants waited patiently, discussed with others or demonstrators, or occupied themselves with an extra board from the Metric System module. In the future, twice as many demonstrators will offer the strength of materials module to avoid waiting and to offer this well-received module to all participants.

Finally, it is important to note that the students and staff involved in this project learned about adapting science and including individuals with disabilities in scientific activities. Additional modules are currently being designed and tested as a continuing effort on our part to provide scientific education to this underserved population. 


\section{ASSOCIATED CONTENT}

Supporting Information

Full module description and answers to select open-ended questions. This material is available via the Internet at http:// pubs.acs.org.

\section{AUTHOR INFORMATION}

Corresponding Author

*E-mail: Er12@rice.edu

Authors Contribution

A. S. designed, constructed, and demonstrated the Metric System module. R. N. designed, constructed, and demonstrated the Strength of Materials module. E. V. designed, constructed, and demonstrated the Materials Transparency module. D. F. S designed and constructed the Hearing the Electromagnetic Spectrum module, E. B. demonstrated it. E. R. helped in the design of all the experiments, managed the preliminary and final testing, served as the activity coordinator, collated the data, and wrote the paper. All authors have analyzed data, participated in preliminary testing, edited the paper, and contributed to the Supplementary Information.

\section{ACKNOWLEDGMENTS}

The authors acknowledge financial support from the Materials Research Society Foundation. E. B., D. F. S. and E. V. acknowledge support from the National Science Foundation Graduate Research Fellowship Program under grant number 1450681. A. S. acknowledges support from the Welch Foundation under grant number L-C-0004. The authors wish to thank Gibson Duterroil and Melinda Benjumea from the Houston Lighthouse for their support, as well as Carolyn Nichol, Tim Paul, and Lawrence Tauzin for helpful discussions.

\section{REFERENCES}

1. Bell, E. C.; Mino, N. M. Blind and Visually Impaired Adult Rehabilitation and Employment Survey: Final Results. J. Blindness Innov. Res. 2013, 3 (1), https://nfb.org/images/nfb/publications/jbir/jbir13/jbir030101abs.html (accessed 30 Sept. 2016) 
2. Cornell University Employment and Disability Institute, http:// www.disabilitystatistics.org/reports/acs.cfm?statistic $=2$ (accessed 30 Sept. 2016)

3. United States Census Bureau, 2014 Census. http://www.census.gov/ (accessed 30 Sept. 2016).

4. Mason, H.; McCall, S. Visual Impairment: Access to Education for Children and Young People; Routledge: New York, 2013.

5. Davis, P. Including Children with Visual Impairment in Mainstream Schools: A Practical Guide; Routledge: New York, 2013.

6. Wedler, H. B.; Boyes, L.; Davis, R. L.; Flynn, D.; Franz, A.; Hamann, C. S.; Harrison, J. G.; Lodewyk, M. W.; Milinkevich, K. A.; Shaw, J. T.; Tantillo, D. J.; Wang, S. C. Nobody Can See Atoms: Science Camps Highlighting Approaches for Making Chemistry Accessible to Blind and Visually Impaired Students. J Chem Educ. 2014, 91 (2), 188-194.

7. Miecznikowski, J. R.; Guberman-Pfeffer, M. J.; Butrick, E. E.; Colangelo, J. A.; Donaruma, C. E. Adapting Advanced Inorganic Chemistry Lecture and Laboratory Instruction for a Legally Blind Student. J Chem. Educ. 2015, 92 (8), 1344-1352.

8. Supalo, C. A.; Hill, A. A.; Larrick, C. G. Summer Enrichment Programs to Foster Interest in Stem Education for Students with Blindness or Low Vision. J Chem. Educ. 2014, 91 (8), 1257-1260.

9. Lunsford, S. K.; Bargerhuff, M. E. A Project to Make the Laboratory More Accessible to Students with Disabilities. J. Chem. Educ. 2006, 83 (3), 407-409.

10. Pence, L. E.; Workman, H. J.; Riecke, P. Effective Laboratory Experiences for Students with Disabilities: The Role of a Student Laboratory Assistant. J. Chem. Educ. 2003, 80 (3), 295-298.

11. Neely, M. B. Using Technology and Other Assistive Strategies to Aid Students with Disabilities in Performing Chemistry Lab Tasks. J. Chem. Educ. 2007, 84 (10), 1697-1701.

12. Kamijo, H.; Morii, S.; Yamaguchi, W.; Toyooka, N.; Tada-Umezaki, M.; Hirobayashi, S. Creating an Adaptive Technology Using a Cheminformatics System to Read Aloud Chemical Compound Names for People with Visual Disabilities. J. Chem. Educ. 2016, 93 (3), 496-503.

13. Riendl, P. A.; Haworth, D. T. Chemistry and Special Education. J. Chem. Educ. 1995, 72 (11), 983-986.

14. Moore, E. B. Confchem Conference on Interactive Visualizations for Chemistry Teaching and Learning: Accessibility for Phet Interactive Simulations-Progress, Challenges, and Potential. J. Chem. Educ. 2016, 93 (6), 1160-1161.

15. Harshman, J.; Bretz, S. L.; Yezierski, E. Seeing Chemistry through the Eyes of the Blind: A Case Study Examining Multiple Gas Law Representations. J. Chem.

Educ. 2013, 90 (6), 710-716.

16. Supalo, C. Techniques to Enhance Instructors' Teaching Effectiveness with Chemistry Students Who Are Blind or Visually Impaired. J. Chem. Educ. 2005, 82 (10), 1513-1518.

17. Supalo, C. A.; Isaacson, M. D.; Lombardi, M. V. Making Hands-on Science Learning Accessible for Students Who Are Blind or Have Low Vision. J. Chem. Educ. 2014, 91 (2), 195-199.

18. Central Intelligence Agency. The World Factbook, Appendix G: Weights and Measures. https://www.cia.gov/library/publications/resources/the-worldfactbook/print/print_AppendixG.pdf (accessed 30 Sept. 2016).

19. National Institute of Health and Friends of the National Library of Medicine, Leading Causes of Blindness. In NIH Medline Plus; 2008; Vol. 3, p 14.

20. Callister, W. D.; Rethwisch, D. G. Fundamentals of Materials Science and Engineering: An Integrated Approach; Wiley: Hoboken, 2012. 
